\title{
OPTIMIZATION OF THE SINGLE STAGGERED WIRE AND TUBE HEAT EXCHANGER
}

\author{
I Made Arsana, Susianto, Kusno Budhikarjono, and Ali Altway* \\ Department of Chemical Engineering, Sepuluh ,Nopember Institute of Technology (ITS), Surabaya, Indonesia \\ *E-Mail: alimohad@chem-eng.its.ac.id
}

\begin{abstract}
Wire and tube heat exchanger consists of a coiled tube, and wire is welded on the two sides of it in normal direction of the tube. Generally, wire and tube heat exchanger uses inline wire arrangement between the two sides, whereas in this study, it used staggered wire arrangement that reduces the restriction of convection heat transfer. This study performed the optimization of single staggered wire and tube heat exchanger to increase the capacity and reduce the mass of the heat exchanger. Optimization was conducted with the Hooke-Jeeves method, which aims to optimize the geometry of the heat exchanger, especially on the diameter $(\mathrm{dw})$ and the distance between wires (pw). The model developed to present heat transfer correlations on single staggered wire and tube heat exchanger was valid. The maximum optimization factor obtained when the diameter wire was $0.9 \mathrm{~mm}$ and the distance between wires (pw) was $11 \mathrm{~mm}$ with the $\mathrm{f}_{\text {ref }}$ value $=$ 1.5837. It means that the optimized design only using mass of $59,10 \%$ and could transfer heat about $98,5 \%$ from the basis design.
\end{abstract}

Keywords: Single staggered wire and tube heat exchanger, heat exchanger capacity, heat exchanger mass, geometry optimization.

\section{INTRODUCTION}

Heat exchanger is an equipment used to exchange energy in the form of heat between different temperature fluid circulation which can occur through direct or indirect contact (Pitts and Sissom, 1977). One of the applications of heat exchange principles is in wire and tube heat exchanger (Kumra et al., 2013). This heat exchanger is belonging to the type of extended surface heat exchanger where wire functioning as fin is installed to the tube which channels hot fluid in order to increase heat transfer surface area and then increase heat transfer rate (Srinivasan and Shah, 1997). Mechanically, wire also functions to support tube configuration (Petroski and Clausing, 1999).

Wire and tube heat exchanger consists of coiled tube, and wire welded on the two sides of it in normal direction of the tube (Witzel and Fontaine, 1957). Generally this heat exchanger uses the array of inline wire (simetry) between both its sides (Samana et al., 2012), but this research used the array of staggered wire so that it decreases the resistance of convection heat transfer. The effort was conducted by the researcher in the field of cooler to expand a new design in the certain part which will give the effect of increasing the ability of the heat exchanger and lessen the use of construction materials (Jaluria, Y., 2007). This heat exchanger has been widely used to dissipate heat from hot fluid which flows through a tube as a condenser of a small air refrigeration system (refrigerator) to condense fluid which flows in tube or applied only as fluid cooler that flows in tube without happening to the phase change (Tanda and Tagliafico, 1997). Nevertheless, studies on the optimization of the heat exchanger have not been done a lot.

Bansal and Chin (2003) developed the computer model for condenser on the condition of free convection. This study used the same method as Tagliafico and Tanda (1997) to get the heat transfer coefficient of free convection. For model validation, it was performed by comparing the modelling result with total heat load from condenser. From the result of data verification, it was obtained that the deviation of heat load is $\pm 10 \%$.
Based on the modelling result above, Bansal and Chin (2003) performed optimization of wire and tube condenser. This optimization proposed optimization factors of heat load ratio permodel condenser mass with heat load per mass from the carly model condenser. By changing diameter wire the distance between wires and diameter tube, it obtained the design of the optimum condenser, which is $3 \%$ heat load increase with $6 \%$ mass condenser decrease.

Pradeep Kumara (2011) performed optimization of a domestic condenser, that is model NST 200 by using the model developed by Tagliafico and Tanda which aimed to increase heat transfer and decrease the production cost of condenser. The result shows that modified condenser can increase the heat transfer as big as $32,9 \%$ and decrease $19 \%$ of the production cost from the existed design (present condenser).

Some of the researches above averagely used wire and tube heat exchanger with inline arrangement design, so this research conducted a new study using single staggered configuration between two sides of heat exchanger. With the position of staggered wire, the phenomena of mergering thermal boundary layer will not happen because the position of wires faced each other between both of heat exchanger sides (Incropera, 1990). Next, almost all researchers in making optimization have not entered optimum wire space variable based on thermal boundry layer analysis as the introduction study.

Based on the thoughts above, a study about optimization of wire and tube heat exchanger by using single staggered wire and tube heat exchanger needs to be performed to obtain the optimum design. The optimum design meant is to reach the performance of heat exchanger as maximum as possible by using fabrication material as minimum as possible.

\section{METHODOLOGY}

To perform the optimization of single staggered wire and tube heat exchanger, we need a model development first. To get the heat transfer of each element $\left(Q_{\text {ele }}\right)$, it needs the calculation of the heat transfer 
coefficient by using semi empirical correlation from Tagliafico and Tanda (1997) for every element. Then, the total heat is the number of the heat transferred from every element. The simulation used the element finite method with the assist of MATLAB program (Kwon Young, 1997), where the element of a heat exchanger is divided into some element units. Each modelling element consists of a tube as long as the pitch wire (pw) and a wire as a fin as long as the pitch tube (pt) with the entrance and exit flows of every element as the following figure-1.

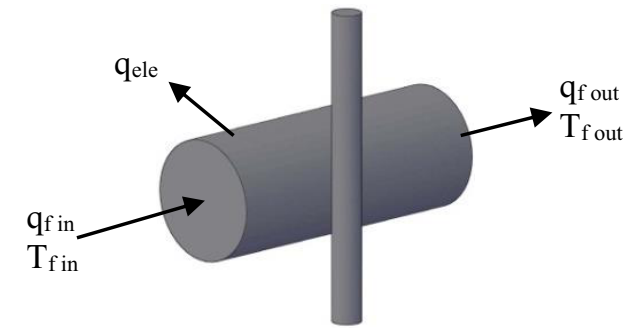

Figure-1. One element of heat exchanger in the element finite method

The heat transferred by every element is $\left(Q_{\text {ele }}\right)$ and then the number of all $Q_{\text {ele }}$ is the total heat transferred by the heat exchanger $\left(\mathrm{Q}_{\text {total }}\right)$. The validation was conducted by comparing the modelling element surface temperature with the experiment results where the element average temperature $\left(\mathrm{T}_{\mathrm{ex}}\right)$ is calculated with the equation as follows:

$$
T_{e x}=\frac{\left(T_{t o}+G P \cdot \eta_{W}\left(T_{t o}-T_{\infty}\right)+G P \cdot T_{\infty}\right)}{(1+G P)}
$$

Where: $T_{e x}=$ element average temperature

$$
\begin{aligned}
T_{t o} & =\text { tube outside temperature } \\
G P & =\text { geometry parameter } \\
\eta_{W} & =\text { wire efficiency } \\
T_{\infty} & =\text { room temperature }
\end{aligned}
$$

By developing a new geometry parameter $(G P)$ based on the geometry characteristics of the single staggered wire and tube heat exchanger with only one wire, that is:

$$
G P=\left(\frac{p_{t}}{d_{t o}}\right)\left(\frac{d w}{p w}\right)
$$

For optimization procedure has been used optimization factor as follows (Bansal and Chin, 2003):

$$
f=\frac{Q / W}{Q_{0} / W_{0}}
$$

Where $\mathrm{Q}$ is the capacity of optimized heat exchanger and $\mathrm{W}$ is the heat exchanger mass, but $\mathrm{Q}_{0}$ and $\mathrm{W}_{\mathrm{o}}$ are the capacity and mass of basis design heat exchanger from local design. In this research, the heat exchanger design used as basis is a wire and tube heat exchanger with the specifications as follows:
- Exchanger $(\mathrm{H})$ $: 445$
- Width of heat exchanger (wire): 431
- Width of heat exchange (tube : 476
$\mathrm{mm}$
- Length of tube : $6416 \mathrm{~mm}$
- Diameter tube outside
$: 4.8 \quad \mathrm{~mm}$
- Diameter tube inside
$: 3.2 \mathrm{~mm}$
- Diameter wire
$: 12 \mathrm{~mm}$

This research has been observed to obtain the maximum condition in order to optimize the optimization factor. The variable designs manipulated are:

- Diameter Wire (dw)

- Distance between Wire (pw)

The optimization theory said that determining the early point at Hooke-Jeeves method very much influenced the optimization result. Therefore, to determine the initial point, this research has used thermal boundary layer analysis (Romero-Méndez, 2000), with this analysis convergence process and the exact of optimum value obtained in maximum. Based on the analysis, it was obtained that the optimum value of pitch wire (pw) was \pm $9 \mathrm{~mm}$.

However, wire diameter was $1.2 \mathrm{~mm}$ where tube diameter and the distance between tubes were kept constantly, which were $5 \mathrm{~mm}$ and $40 \mathrm{~mm}$, respectively. Entrance fluid temperature of heat exchanger was $60{ }^{\circ} \mathrm{C}$, whereas fluid flow rate (oil) was $0.006 \mathrm{~kg} \cdot \mathrm{s}^{-1}$ and environment temperature was $30{ }^{\circ} \mathrm{C}$.

\section{RESULTS AND DISCUSSIONS}

In this case, the model used has been validated with the result of experiment performed by using a set of single staggered wire and tube heat exchanger with the specification as follows:

- Height of heat exchanger $(\mathrm{H}) \quad: 445 \mathrm{~mm}$

- Diameter tube outside (dto) : $4.8 \mathrm{~mm}$

- Diameter tube inside (dti) : $3.2 \mathrm{~mm}$

- Diameter wire (dw) : $1.2 \mathrm{~mm}$

- Distance between wires (pw) : 7, 14, 21mm,

- Number of tube : 12 coils

- Width of heat exchanger (W) : $431 \mathrm{~mm}$

- Distance between tubes (pt) :40 m

Operation conditions:

- Fluid flow rate

- Entrance fluid temperature

- Envinronment temperature

- Distance between wires

- Number of tubes

- Material of heat exchanger
$: 0.006 \mathrm{~kg} \cdot \mathrm{s}^{-1}$

: $60{ }^{\circ} \mathrm{C}$ dan $70{ }^{\circ} \mathrm{C}$

$: 30{ }^{\circ} \mathrm{C}$

$: 7 \mathrm{~mm}$

: $40 \mathrm{~mm}$

: Steel

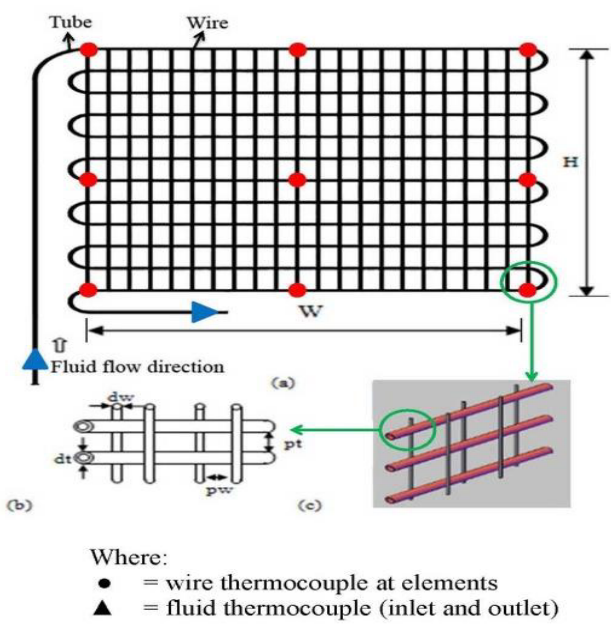

Figure-2. Single staggered wire and tube heat exchanger geometry for validating 
Validation was performed by comparing with the temperature of experiment result at the certain elements with the calculation temperature at the same elements. For heat exchanger with pw: $7 \mathrm{~mm}$, the model elements are at elements no: 1, 96, 189, 283, 378, 474, 567, 661, and 756 . Then for $\mathrm{pw}=14 \mathrm{~mm}$, the model elements are at elements no: $1,49,96,144,192,241,288,336$, and 384. But for pw $=21$, the elements are at elements no: $1,34,66,99,132$, $166,198,231$, and 264. The operation condition of calculation must be the same as the experiment condition.

As the early step in performing this validation, we performed the early condition trial of surface temperature distribution of heat exchanger by mapping infrared thermography instrument at the whole heat exchanger surfaces. The result of observation with infrared thermography obtained the early description of temperature distribution as follows.

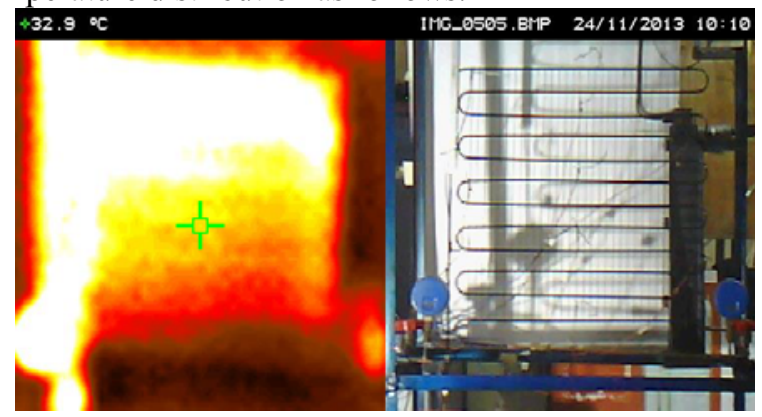

Figure-3. Mapping of surface temperature distribution of heat exchanger using infrared thermography

The Figure above is the result on infrared thermography photo that shows surface hot area of heat exchanger after being flown by hot fluid (hot oil). White area is part of surface with high temperature area because that area is a part of entrance fluid to heat exchanger where the fluid temperature is relatively high. It is then followed by yellowish area which has medium temperature that is a part of wire array in the middle part of overall heat exchanger surface area. But a part of red color is the area which has low temperature because at that part fluid leaves the heat exchanger. From this early description, it can be seen that the temperature decreases together with release of heat performed by the array of wires which functions as fins, and finally cold fluid will leave the heat exchanger.

After being known the trend of temperature characteristic at heat exchanger surface generally, it is then performed the measurement of surface temperature distribution accurately by using thermocouple measurement at each element point of heat exchanger. The following is the temperature of element point (9 measurement points) for heat exchanger with pw (pitch wire) $=7 \mathrm{~mm}$ with entrance temperature at $60{ }^{\circ} \mathrm{C}$.

Table-1. Distribution of element temperature at heat exchanger $\mathrm{pw}=7 \mathrm{~mm}$

\begin{tabular}{|c|r|r|}
\hline Element to & $\begin{array}{c}\text { Temp. } \\
\text { experiment }\end{array}$ & $\begin{array}{c}\text { Temp. } \\
\text { calculation }\end{array}$ \\
\hline $\mathbf{1}$ & 49.94649 & 49.425 \\
\hline $\mathbf{9 6}$ & 46.20797 & 46.78 \\
\hline $\mathbf{1 8 9}$ & 44.43979 & 44.51 \\
\hline $\mathbf{2 8 3}$ & 42.98776 & 41.093 \\
\hline $\mathbf{3 7 8}$ & 40.53906 & 39.608 \\
\hline
\end{tabular}

\begin{tabular}{|l|r|r|}
\hline $\mathbf{4 7 4}$ & 37.79227 & 37.355 \\
\hline $\mathbf{5 6 7}$ & 36.10708 & 36.385 \\
\hline $\mathbf{6 6 1}$ & 35.28887 & 34.8972 \\
\hline $\mathbf{7 5 6}$ & 34.29777 & 34.255 \\
\hline
\end{tabular}

Based on the observation result data at 9 thermocouple points located at the elements above the difference from modeling, some result data will be obtained. The analysis result shows that the error percentage between the observation and the modeling results are $1.36 \%$ and temperature profile of each point based on the observation result and modeling can be presented in the following figure-4.
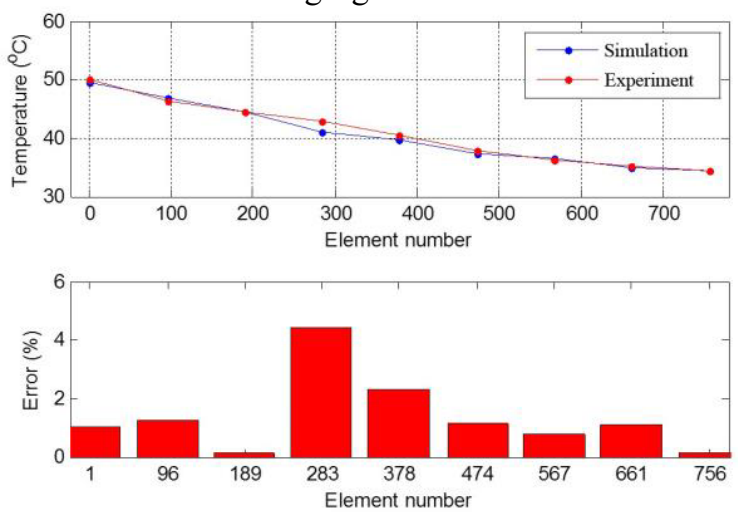

Figure-4. Temperature validation graphic on each element for $\mathrm{pw}=7 \mathrm{~mm}$

Heat exchanger with $\mathrm{pw}=14 \mathrm{~mm}$ obtained the element temperature distribution from 9 points of thermocouple placement at the elements below (table-2). Data was taken at the entrance temperature of heat exchanger of $60{ }^{\circ} \mathrm{C}$ and room temperature of $30{ }^{\circ} \mathrm{C}$.

Table-2. Distribution of element temperature at heat exchanger $\mathrm{pw}=14 \mathrm{~mm}$

\begin{tabular}{|c|r|r|}
\hline Element to & $\begin{array}{c}\text { Temp. } \\
\text { experiment }\end{array}$ & $\begin{array}{c}\text { Temp. } \\
\text { calculation }\end{array}$ \\
\hline $\mathbf{1}$ & 48.75064 & 49.6487 \\
\hline $\mathbf{3 4}$ & 46.00827 & 47.218 \\
\hline $\mathbf{6 6}$ & 42.55736 & 45.104 \\
\hline $\mathbf{9 9}$ & 42.35471 & 41.84 \\
\hline $\mathbf{1 3 2}$ & 38.34888 & 40.395 \\
\hline $\mathbf{1 6 6}$ & 36.25591 & 38.155 \\
\hline $\mathbf{1 9 8}$ & 34.60221 & 37.17 \\
\hline $\mathbf{2 3 1}$ & 33.52144 & 35.6335 \\
\hline $\mathbf{2 6 4}$ & 32.14177 & 34.957 \\
\hline
\end{tabular}

Based on the analysis of the error percentage, we obtained a deviation of $4.96 \%$ between data from experiment result and modeling. Temperature profile of each point based on observation result and modeling can be presented in the following figure- 5 . 

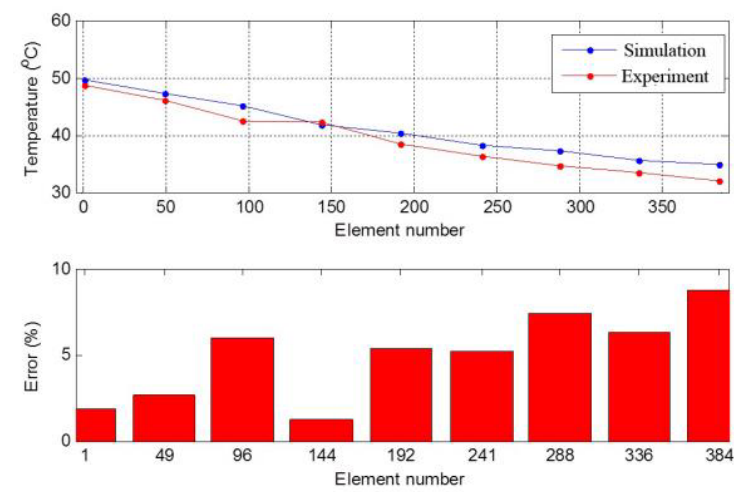

Figure-5. Temperature validation graphic on each element for $\mathrm{pw}=14 \mathrm{~mm}$

Based on both data verification performed between the experiments and modeling results, we obtained its error percentage which is relatively small i.e. less than 5\%. This case means that the developed model is considered to be good enough and accurate to perform optimization.

The change of diameter wire (dw) and pitch wire (pw) gives a very significant impact to the total heat which can be transferred by wire and tube. Besides, it influences the coefficient of heat transfer at outside part of tube $h_{0}$. Increasing or decreasing the number of wires on tubes also influences the area of heat transfer surface. Besides the number of wires, diameter also influences the area of heat transfer surface. By changing geometry parameters, it is expected to obtain maximum total heat which can be transferred to the environment. But only if total heat is maximized, of course theoretically, the increase in the number of many wires will improve heat transfer rate and finally the materials used at fabrication will also increase. Therefore, beside heat transfer rate, it will also be important to consider the mass used in making wires and tube. By performing optimization, it is expected that wire and tube can transfer heat at the maximum with material mass used as little as possible.

In this research, the basis design used as a basis is a heat exchanger with the specifications as follows:

- Height of heat exchanger $(\mathrm{H}): 445 \mathrm{~mm}$

- Width of heat exchanger (wire): $431 \mathrm{~mm}$

- Width of heat exchange (tube : $476 \mathrm{~mm}$

- Length of tube (total) : $6416 \mathrm{~mm}$

- Diameter tube outside $\quad: 4.8 \mathrm{~mm}$

- Diameter tube inside $\quad: 3.2 \mathrm{~mm}$

- Diameter wire $\quad: 1.2 \mathrm{~mm}$

- Distance between wires $\quad: 7 \mathrm{~mm}$

- Number of tube : 12 coils

- Distance between tubes $\quad: 40 \mathrm{~m}$

- Material of heat exchanger : steel

By using the model developed in this research, the obtained result of a basis heat exchanger is tabled as follows:

Table-3. $\mathrm{Q}_{\text {total }}, \mathrm{f}_{0}$ for basis heat exchanger

\begin{tabular}{|l|r|l|}
\hline Parameters & Values & Unit \\
\hline Qtotal $^{\text {Massa wire }}$ & 121.7274 & Watt \\
\hline $\begin{array}{l}\text { and tube } \\
\mathrm{f}_{0}=\mathrm{Q}_{\text {total }} / \\
\text { massa }\end{array}$ & 112.8359 & $\mathrm{~kg}$ \\
\hline $\mathrm{f}_{\mathrm{ref}}=\mathrm{f} / \mathrm{f}_{0}$ & 1 & \\
\hline
\end{tabular}

Since in this research $f_{\text {ref }}$ will be maximized, there is a possibility that $\mathrm{Q}_{\text {total }}$ will be less than $\mathrm{Q}_{\text {total }}$ basis. Althought $Q_{\text {total }}$ is less; maximum $f_{\text {ref }}$ will give a comparison between $\mathrm{Q}_{\text {total }}$ and the most maximum wire mass. It means that a little mass can transfer high enough heat, in which its value can approach, be equal to or even bigger than $\mathrm{Q}_{\text {total }}$ basis. The following presented a table (table 4) and graphic (figure 6) of the influence of wire $(\mathrm{dw})$ and distance between wires (pw) to optimization factor $\left(f_{\text {ref }}\right)$.

Table-4. Influence of pw and dw to $\mathrm{f}_{\text {ref }}$

\begin{tabular}{|l|l|l|l|l|l|l|l|}
\hline $\begin{array}{l}\text { dwlpw } \\
(\mathbf{m})\end{array}$ & 0.005 & 0.007 & 0.008 & 0.009 & 0.01 & 0.011 & 0.012 \\
\hline 0.0008 & 1.4832 & 1.5531 & 1.5576 & 1.56 & 1.5811 & 1.5785 & 1.5528 \\
\hline 0.0009 & 1.4306 & 1.5322 & 1.5468 & 1.5577 & 1.5828 & 1.5837 & 1.5609 \\
\hline 0.001 & 1.3603 & 1.4968 & 1.5244 & 1.543 & 1.5481 & 1.579 & 1.5603 \\
\hline 0.0011 & 1.2974 & 1.4507 & 1.4896 & 1.5174 & 1.53 & 1.565 & 1.5515 \\
\hline 0.0012 & 1.2352 & 1.3972 & 1.4459 & 1.4827 & 1.5032 & 1.5427 & 1.5351 \\
\hline 0.0013 & 1.176 & 1.3396 & 1.3961 & 1.4408 & 1.4689 & 1.5131 & 1.5118 \\
\hline 0.0014 & 1.1208 & 1.2806 & 1.3423 & 1.3936 & 1.4287 & 1.4774 & 1.4826 \\
\hline 0.0015 & 1.0699 & 1.2221 & 1.2868 & 1.343 & 1.3841 & 1.4369 & 1.4485 \\
\hline
\end{tabular}

The yellow highlights on some values in the table show the highest $f_{\text {ref }}$ for each diameter wire. From the table above, it is known that the result of maximum $f_{\text {ref }}$ is obtained when the diameter wire is the same as $9 \mathrm{~mm}$ and the distance between wires is $11 \mathrm{~mm}$ with $\mathrm{f}_{\text {ref }}$ value is 1.5837. In table- 4 above, the minimum value pw is limited at $5 \mathrm{~mm}$ and $\mathrm{dw}$ at $8 \mathrm{~mm}$, this is because of the fabrication limitation in making those tools. If the values of pw and $\mathrm{dw}$ are less than the boundary, it will be difficult in fabrication, it is even impossible for the size of dw and pw which are very little. Optimization method of HookeJeevess is the solution of optimization without limitation. Theoretically, maximum $f_{\text {ref }}$ is obtained when the values of pw and $d w$ are very small. This case can be seen at the graphic, trending at the red diagonal which increasing more and more because of the decrease of pw and dw. However, because there is a boundary, the maximum $f_{\text {ref }}$ can be obtained as it has been explained before. Graphically, the profile of pw and dw's influence to $f_{\text {ref }}$ is presented as follows (figure-6):

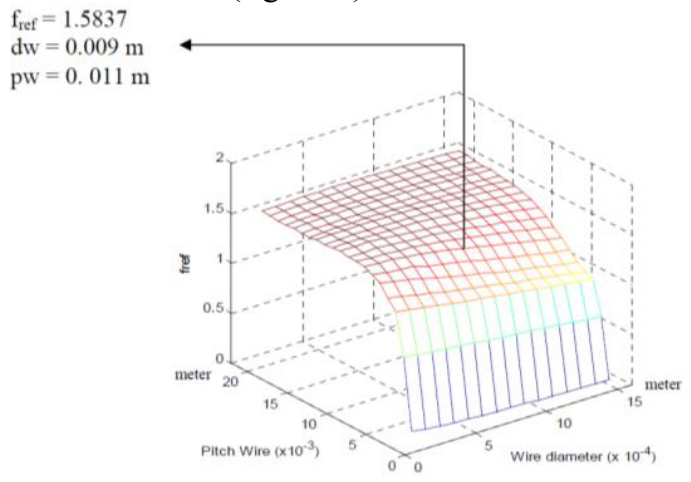

Figure-6. Graphic of dw and pw influence to $\mathrm{f}_{\mathrm{ref}}$

It has been explained before that from the graphic above, it seems that the optimum $\mathrm{f}_{\text {ref }}$ is obtained at dw 0.9 $\mathrm{mm}$ and $\mathrm{pw}=11 \mathrm{~mm}$ with the value of $\mathrm{f}_{\text {ref }}=1.5837$. However, from the graphic above, it cannot be determined how much heat is transferred by heat exchanger. The influence of $\mathrm{dw}$ and $\mathrm{pw}$ to how much heat transferred will be presented at the following table 5 . 
Table-5. The influence of $\mathrm{pw}$ and $\mathrm{dw}$ to $\mathrm{Q}_{\text {tot }}$

\begin{tabular}{|l|l|l|l|l|l|l|l|}
\hline dw/pw & 0.005 & 0.007 & 0.008 & 0.009 & 0.01 & 0.011 & 0.012 \\
\hline 0.0008 & 120.86 & 120.2507 & 119.7495 & 119.3572 & 119.3819 & 119.055 & 118.3943 \\
\hline 0.0009 & 121.513 & 121.0994 & 120.6373 & 120.2519 & 120.2756 & 119.9214 & 119.2145 \\
\hline 0.001 & 121.791 & 121.8046 & 121.4058 & 121.0528 & 120.5808 & 120.7312 & 119.9919 \\
\hline 0.0011 & 122.296 & 122.3841 & 122.0586 & 121.7564 & 121.3069 & 121.4778 & 120.7202 \\
\hline 0.0012 & 122.808 & 122.8627 & 122.6061 & 122.3646 & 121.9526 & 122.157 & 121.3947 \\
\hline 0.0013 & 123.356 & 123.2683 & 123.064 & 122.884 & 122.5189 & 122.767 & 122.0123 \\
\hline 0.0014 & 123.959 & 123.6277 & 123.4509 & 123.3249 & 123.0101 & 123.3083 & 122.5717 \\
\hline 0.0015 & 124.624 & 123.965 & 123.786 & 123.6999 & 123.4329 & 123.7839 & 123.0733 \\
\hline
\end{tabular}

When the condition of $f_{\text {ref }}$ is maximum, the heat transferred is only 119.9214 watt, which was only $98.5 \%$ from the basis total heat. However, the mass used is less, i.e. $0.6376 \mathrm{~kg}$ that means only $59.10 \%$ from the basis mass, or on the other hand, it has decreasing material mass used until $40.89 \%$. In table-5, it can be seen that the smaller the distance between wires, the higher the $\mathrm{Q}_{\text {total }}$ and an increase in diameter will also cause an increase in $\mathrm{Q}_{\text {total }}$. On the other hand, if $\mathrm{pw} \leq \mathrm{dw}$, the system will be considered as tube with arrangement of fins like a plate, which means that $\mathrm{Q}_{\text {total }}$ will be smaller.

Figure-7 explains the graphic of the ability of releasing heat from each heat exchanger:

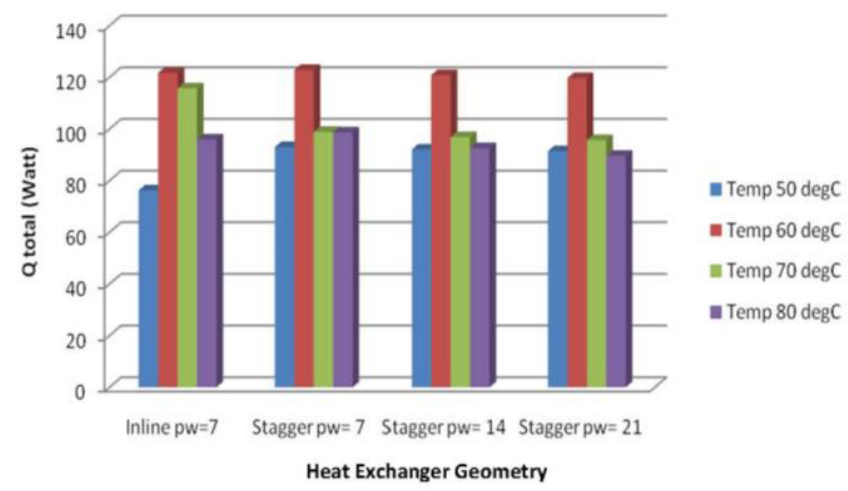

Figure-7. The influence of heat exchanger geometry to heat transfer rate.

From the above graphic, the rate of total heat transfer (watt) released by each heat exchanger can be seen. The heat exchanger with $\mathrm{pw}=7 \mathrm{~mm}$ inline (basis) releases the highest heat rate because this heat exchanger has the biggest heat transfer surface. Then it is continuously followed by heat exchanger of $\mathrm{pw}=7 \mathrm{~mm}$ staggered, heat exchanger $\mathrm{pw}=14 \mathrm{~mm}$ staggered, and the last is heat exchanger of $\mathrm{pw}=21 \mathrm{~mm}$ staggered which are suitable for total surface area of each heat exchanger. The interesting thing from the figure above is the heat exchanger of $\mathrm{pw}=7$ staggered has less number of wires but it can release heat not much of a different from basis heat exchanger which has much more number of wires. This case means that heat exchanger of $\mathrm{pw}=7$ staggered has a high optimization factor because it has the ability of releasing high enough heat with low enough material mass.

\section{CONCLUSIONS}

Based on the research result data and analysis performed, some important things connecting to the optimization of single staggered wire and tube heat exchanger can be concluded as follows:

A model has been developed to present heat transfer at single staggered wire and tube heat exchanger i.e. one heat exchanger element which consists of one tube as long as pitch wire and a wire which as long as pitch tube was valid. A validation was performed with the approach of element temperature parameter at 9 points thermocouple with the error percentage is less than $5 \%$ between the results of experiment and modeling. Based on the optimization study by Hooke-Jeevess, method it could be identified that the maximum optimization factor $\left(f_{r e f}\right)$ was at the diameter wire $(\mathrm{dw})$ of $0.9 \mathrm{~mm}$ and the distance between wires was $11 \mathrm{~mm}$ with the value of $\mathrm{f}_{\text {ref }}$ is 1.5837 . It means that the optimized design is only using $59.10 \%$ mass and can transfer $98.5 \%$ heat from the basis heat exchanger. An increase in the number of wires $(\mathrm{N})$ will increase the heat transfer rate from heat exchanger as long as the convection coefficient is not influenced by pitch fin.

\section{ACKNOWLEDGEMENT}

We thank DIKTI and Heat Transfer Laboratory of Chemical Engineering Department of ITS for all helps and supports for this research.

\section{REFERENCES}

Bansal, P.K., T.C. Chin. 2002. Design and modelling of hot-wall condensers in domestic refrigerators. Applied Thermal Engineering, Vol. 22, pp. 1601-1617.

Bansal, P.K., and Chin, T.C. 2003. Modelling and optimisation of wire-and-tube condenser. International Journal of Refrigeration, Vol. 26, pp. 601-613.

Incropera, Frank P., DeWitt, David P. 1990. Fundamentals of Heat and Mass transfer. John Wiley \& Sons, New York.

Jaluria, Y. 2007. Design and Optimization of Thermal Systems. Second Edition, McGraw-Hill, New York.

Kumara, Pradeep. 2011. Optimization Of Performance And Assessment Of Material Cost Of The Refrigerator Condenser. Master Of Science Thesis, KTH School of Industrial Engineering and Management.

Kumra, A., Rawal, N., and Samui, P. 2013. Prediction of heat transfer rate of a wire-on-tube type heat exchanger: An Artifical Intelegence approach. Procedia Engineering, Vol. 64, pp. $74-83$.

Kwon Young W., Bang Hyochoong. 1997. The Finite element methode using MATLAB, $3^{\text {rd }}$ edition, CRC Press, New York.

Pitts, D and Sissom, L. 1977. Heat Transfer. McGraw-Hill, inc.

Petroski, S.J., and Clausing, A.M. 1999. An Investigation of the Performance of Confined, Saw-Tooth Shaped Wireon-Tube Condensers. University of Illinois at UrbanaChampaign, ACRC TR-153.

Romero-Méndez, R., Sen, M., Yang, K.T., and McClain, R. 2000. Effect of on spacing on convection in a plate fin and tube heat exchanger. Int. J. Heat and Mass Transfer, Vol. 43, pp. 39-51. 
Samana, T., Kiatsiriroat, T., and Nuntaphan, A. 2012. Airside Performance Analysis of Wire-on-tube Heat Exchanger Having Oscillating Heat Pipe as Extended Surface under Natural Convection Condition. Heat Transfer Engineering, Vol. 33, issue 12, pp. 1033-1039.

Srinivasan, V. and Shah, R.K. 1997. Fin Efficiency of Extended Surfaces in Two Phase- Flow. Journal of Heat and Fluid Flow, Vol. 18, pp. 419 - 429.

Tagliafico, L., and Tanda, G. 1997. Radiation and natural convection heat transfer from wire-and-tube heat exchangers in refrigeration appliances. International Journal of Refrigeration, Vol. 20, No. 7, pp. 461-469.

Tanda, G, and Tagliafico, L. 1997. Free Convection Heat Transfer From Wire and Tube Heat Exchangers. Journal of Heat Transfer, Vol. 119, pp. 370 - 372.

Witzell, O.W. and Fontaine, W.E. 1957. Design of Wire and Tube Condensers. Journal of Refrigerating Engineering, Vol. 65, pp. $41-44$. 